\title{
STUDI ANATOMI DAUN DAN BATANG Maesopsis eminii (Rhamnaceae)
}

\author{
Eka Fatmawati Tihurua dan Sunaryo \\ Bidang Botani, Pusat Penelitian Biologi - LIPI \\ Jl. Raya Jakarta - Bogor Km 46. Cibinong 16911 \\ E-mail: herbogor@indo.net.id
}

\begin{abstract}
Maesopsis eminii is one of alien and invasive plant in Indoensia and planted in Resort Bodogol, Gunung Gede Pangrango National Park. The results showed M. eminii has dorsiventral and hypostomatic leaf type with anomocytic stomata, drusse type of $\mathrm{CaCO}_{3}$ crystal, multicellular and uniseriate trichomes in the upper and lower surface. While its stem has variation in its ray initial layer depend on its trunk circumference.
\end{abstract}

Keywords: Maesopsis eminii, anatomi, alien and invasive plant, Gunung Gede Pangrango National Park

\section{PENGANTAR}

Measopsis eminii merupakan jenis tumbuhan yang masuk dalam anggota suku Rhamnaceae. Jenis tumbuhan ini berasal dari daerah Afrika Tropis sehingga sering disebut sebagai kayu Afrika. Beberapa manfaat M. eminii antara lain untuk kebutuhan kayu, serat, bahan bakar organik, sebagai bahan obat, sebagai tumbuhan peneduh dan untuk keperluan agroforestri (Ginoga et al, 2004). Reforestrasi di bidang kehutanan merupakan alasan untuk mendatangkan jenis tumbuhan ini dari habitat aslinya dan menjadikannya sebagai jenis tumbuhan introduksi dibeberapa negara. Saat ini M. emenii telah berkembang menjadi jenis tumbuhan invasif diberbagai negara, antara lain dinegara-negara Tanzania, Puerto Rico, Rwanda (Anonim, 2009a), dan negara-negara di Asia Tenggara, termasuk di Indonesia (Orwa et al, 2009). Tumbuhan ini didatangkan pertama kali di Jawa pada tahun 1920 (Anonim, 2003), dan saat ini $M$. emenii banyak tumbuh di daerah Jawa Barat, khususnya di kawasan Taman Nasional Gunung Gede Pangrango, Resort Bodogol (Sunaryo dan Tihurua, 2010). Jenis tumbuhan ini hidup pada ketinggian 500-1500 m, mampu menyesuaikan terhadap lingkungan, memiliki toleransi hidup yang luas pada beberapa tipe tanah, anakan tumbuhannya juga toleran terhadap naungan sehingga tanaman ini dapat tumbuh juga pada hutan yang belum terganggu. Penyebaran biji-bijinya dibantu oleh burung-burung dan mamalia hutan, periode dormansi biji-bijinya lebih dari 200 hari, tetapi dapat lebih cepat pada kondisi tanah yang lembab (Anonim, 2009b; Orwa et al, 2009). Beberapa kemampuan adaptif tersebut di atas menjadikan jenis ini tumbuh dan berkembang dengan baik di berbagai kawasan, baik kawasan konservasi maupun non konservasi. Kajian jenis maupun ekologi terakhir yang dilakukan oleh Uji dkk. (2010) menunjukkan bahwa $M$. emenii dalam bentuk pohon maupun anak pohon memiliki Nilai Indeks Penting yang cukup tinggi, sehingga dianggap dapat memberikan ancaman bagi kelestarian jenis-jenis tumbuhan asli setempat.

Tujuan dari penelitian ini untuk mengetahui struktur anatomi organ vegetatif $M$. eminii dan penerapannya dalam adaptasi terhadap lingkungan. Studi ini perlu dilakukan karena menurut Anonim (2009b) tumbuhan ini dapat merubah ekosistem antara lain, tingkat keasaman tanah akan bertambah, perubahan komposisi hewan tanah yang akan lebih homogen jenisnya, serta tanah organik di bagian atas hilang.

\section{BAHAN DAN CARA KERJA}

Lokasi pengambilan meterial dilakukan di resort Bodogol, Taman Nasional Gunung Gede Pangrango pada bulan April 2010. Material yang digunakan adalah daun dan batang M. eminii dengan keliling yang berbeda-beda. Metode yang digunakan adalah metode parafin menurut Sass (1951) dengan beberapa modifikasi. Untuk membuat penampang paradermal menggunakan metode menurut Cutler (1978).

Metode parafin menggunakan FAA sebagai larutan fiksatif, dehidrasi menggunakan larutan seri alkohol dan xylol, infiltrasi dengan parafin cair (titik leleh $56-58^{\circ} \mathrm{C}$ ). Pewarnaan menggunakan larutan $2 \%$ safranin dalam alkohol $70 \%$ dan $1 \%$ fast green dalam alkohol absolut. Pembuatan preparat paradermal menggunakan larutan asam nitrit untuk pengambilan permukaan atas dan bawah daun.

Pengamatan dan pengambilan foto menggunakan mikroskop Nikon Eclipse $80 i$. Pengamatan struktur anatomi helaian daun, tangkai daun (petiole) serta batang M. eminii dilakukan pada posisi irisan melintang atau membujur. 


\section{HASIL}

\section{Daun M. eminii}

Daun M. eminii termasuk ke dalam tipe daun dorsiventral, epidermis di permukaan atas dan bawah 1 lapis dan berkedudukan sejajar dengan sel-sel epidermis di sampingnya. Epidermis atas dan bawah berdinding lurus dan berbentuk polygonal. Stomata hanya terdapat di permukaan bawah daun, bertipe anomocytic (Gambar 3). Mesofil yang terdiri dari jaringan parenkim dapat dibedakan antara 2 lapis jaringan tiang (palisade) di bagian atas daun dan jaringan bunga karang (sponge) di bawahnya (Gambar 1B). Kristal dapat ditemui di mesofil bertipe drusse (Gambar 2B). Kutikula di permukaan atas daun
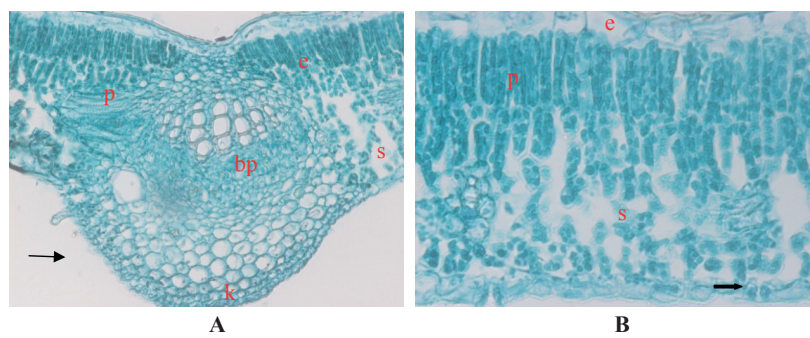

Gambar 1. Irisan melintang daun M.eminii. Gambar di atas memperlihatkan daun $M$. eminii bertipe dorsiventral dengan jaringan palisade $(p)$ dan sponge (s). Stomata hanya terletak di permukaan bawah daun (1 $\mathrm{B}$, tanda panah tebal) dan trikoma (1 A, tanda panah tipis).

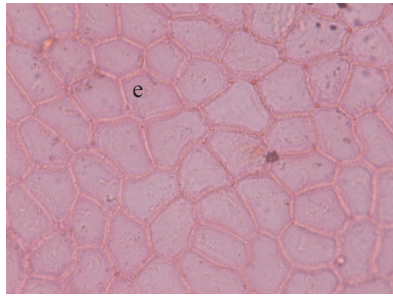

$\mathbf{A}$

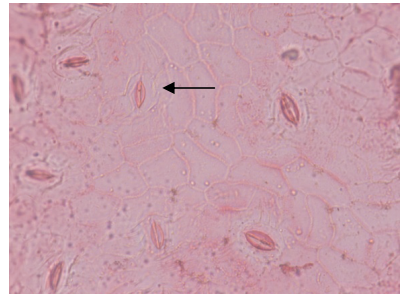

B
Gambar 3. Irisan paradermal daun M. eminii. Sel epidermis berdinding lurus baik di permukaan atas maupun bawah daun (e). Stomata bertipe anomocytic (tanda panah). cukup tebal. Trikoma tidak hanya terletak di permukaan atas tapi juga di permukaan bawah, bertipe multiselular dan uniseriate dengan ujung meruncing atau tumpul (Gambar 1A).

Tangkai daun M. eminii memiliki sistem jaringan pengangkut tunggal berbentuk U (Gambar 2A). Pada tangkai daun ini juga hadir trikoma dan kristal yang bertipe sama dengan helaian daun.

Pada irisan tangensial batang $M$. eminii terlihat kambium yang terdiri atas inisial jejari dengan sel-sel kecil dan inisial fusiform dengan sel-sel memanjang (Gambar 4-5). Inisial jejari pada irisan tangensial batang M. eminii dengan keliling $34 \mathrm{~cm}$ memiliki inisial jejari 1-3 baris sel; $75 \mathrm{~cm}$

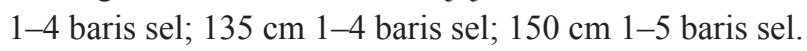

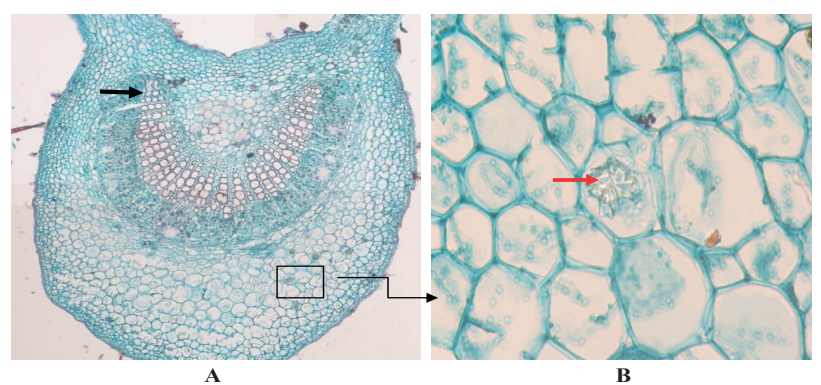

Gambar 2. Irisan melintang petiole $M$. eminii. Tangkai daun $M$. eminii memiliki sistem jaringan pengangkut tunggal berbentuk $U$ (tanda panah hitam) dan trikoma dan kristal yang bertipe sama dengan helaian daun (tanda panah merah, 2B).

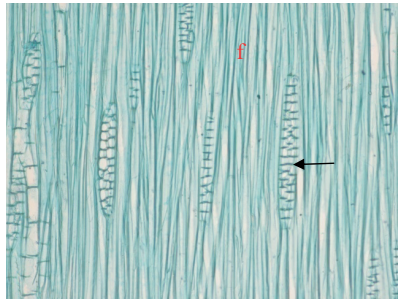

A

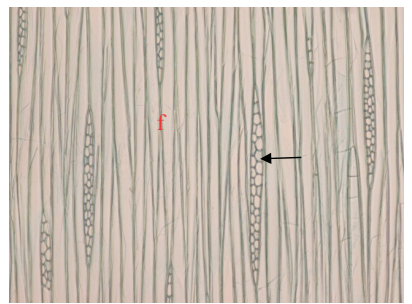

B
Gambar 4. Irisan tangensial batang $M$. eminii dengan keliling 34 $\mathrm{cm}(\mathrm{A})$ dan $75 \mathrm{~cm}(\mathrm{~B})$. Terlihat adanya 2 jenis inisial penyusun kambium yaitu inisial fusiform (f) dan inisial jejari (tanda panah). 


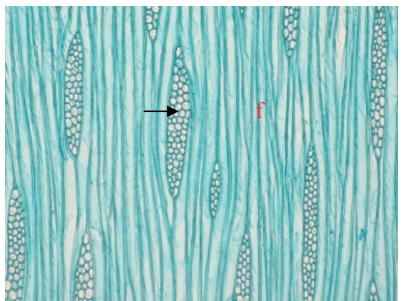

A

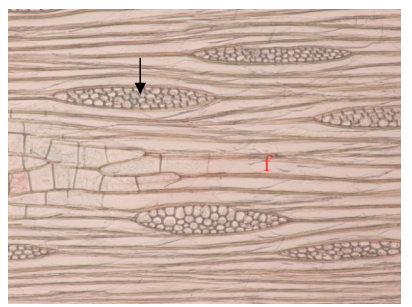

B
Gambar 5. Irisan tangensial batang M. eminii dengan keliling 135 $\mathrm{cm}(\mathrm{A})$ dan $150 \mathrm{~cm}$ (B). Inisal fusiform (f) dan inisial jejari (tanda panah).

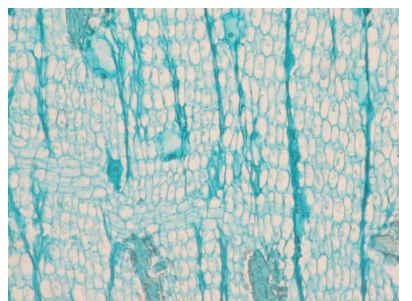

A

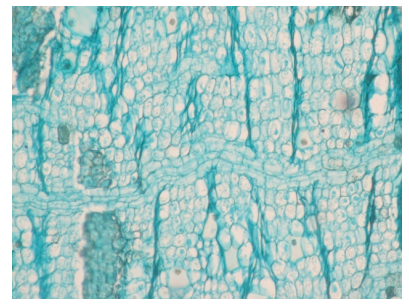

C

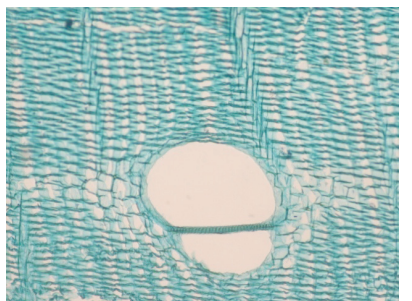

B

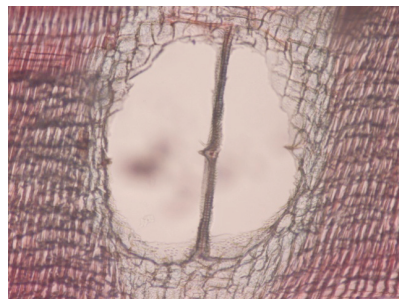

D
Gambar 6. Irisan melintang batang M. eminii dengan keliling $34 \mathrm{~cm}(\mathrm{~A}), 75 \mathrm{~cm}(\mathrm{~B}), 135 \mathrm{~cm}(\mathrm{C})$ dan $150 \mathrm{~cm}(\mathrm{D})$.

\section{PEMBAHASAN}

Secara anatomi pada umumnya anggota suku Rhamnaceae memiliki daun bertipe dorsiventral, terkadang centris atau subcentris dengan rambut sederhana, uniseluler atau uniseriate; stomata bertipe ranunculaceous/rubiaceous/ cruciferous dan umumnya terletak di permukaan bawah daun, walaupun ada yang tercatat di kedua permukaan daun; hipodermis hadir di beberapa jenis; sistem jaringan pengangkut pada tangkai daun tunggal dan terbuka atau berbentuk $U$, atau 3 jaringan pengangkut terpisah, atau terbuka dengan 2 jaringan pengangkut kecil (Metcalfe and Chalk, 1950).

Ada beberapa perbedaan anatomi M. eminii dengan anggota Rhamnaceae lainnya. Pada species ini diketemukan trikoma bertipe multiselular dan uniseriate tetapi Metcalfe and Chalk (1950) menyatakan jika daun Rhamnaceae biasanya memiliki trikoma bertipe uniselular atau uniseriate.
Stomata bertipe anomocytic/ranunculaceous ditemukan hanya di epidermis permukaan bawah daun, ini sesuai yang dinyatakan oleh Metcalfe dan Chalk (1950).

Pada tangkai daun $M$. eminii, sistem jaringan pengangkut yang berbentuk $U$ atau sistem jaringan pengangkut tunggal terbuka seperti yang umum ditemukan pada anggota Rhamnaceae. Selain sistem jaringan pengangkut tersebut, beberapa anggota Rhamnaceae juga memiliki sistem jaringan pengangkut dengan 3 jaringan pengangkut yang terpisah (Metcalfe and Chalk, 1950).

Jenis ini dapat bertahan karena Bodogol menyediakan lingkungan yang sesuai dengan lingkungan asalnya. Selain itu juga tumbuhan dapat tumbuh pada daerah yang terganggu (hutan sekunder) maupun hutan primer yang menyediakan naungan dikarenakan pertumbuhan biji M. eminii tidak tergantung pada penyinaran matahari, tetapi tergantung pada kelembaban tanah (Orwa et al, 2009). Selain itu, menurut Anonim (2009b) seedling dari tumbuhan ini dapat tumbuh di tanah tanpa humus. M. eminii dapat tumbuh secara generatif dengan biji atau secara vegetatif dengan memotong batang/stek. Pertumbuhan secara vegetatif tumbuhan ini sama baiknya dengan pertumbuhan secara generatif.

Penyesuaian daun terhadap lingkungan ditunjukkan dengan beberapa struktur jaringan penyusun daun. Pertama dengan adanya kutikula yang cukup tebal pada M. eminii yang tumbuh di daerah ini karena tanaman ini tumbuh pada tempat terbuka yang terkena sinar matahari langsung. Menurut McDougall (1927) pada tumbuhan yang terekspos memerlukan adanya kutikula untuk membantu mengurangi penguapan air. Struktur kedua yang terlihat adanya perkembangan palisade yang rapat karena terekspos matahari. Selain itu karena tumbuhan ini tumbuh di tempat yang terbuka, sehingga epidermis tidak mengandung klorofil hal ini dinyatakan oleh (McDougall, 1927). Bentuk penyesuaian tumbuhan terhadap lingkungan lainnya berupa kristal yang merupakan hasil dari metabolisme yang harus dikeluarkan. Pada M. eminii kristal hadir dengan bentuk drusse. Menurut McDougall (1927), daun merupakan tempat yang cocok untuk menyimpan kristal $\mathrm{CaCO}_{3}$ karena kristal tersebut akan gugur bersamaan dengan gugurnya daun pada suatu tumbuhan.

Pada irisan tangensial batang, adanya perbedaan jumlah baris inisial jejari kemungkinan menjadi salah satu bentuk penyesuaian $M$. eminii terhadap lingkungan. Karena berdasarkan pengamatan terhadap irisan melintang batang M. eminii menunjukkan semakin besar keliling batang M. eminii maka semakin banyak jumlah baris inisial jejari. Dua macam tipe kambium yang ada pada batang $M$. eminii 
ini merupakan perkembangan sekunder kambium yang umum terjadi di batang tua suatu tumbuhan. Jari-jari pada batang anggota Rhamnaceae umumnya tersusun atas 2-5 sel (Metcafe and Chalk, 1950).

\section{KEPUSTAKAAN}

Anonim, 2003. Penyebaran Jenis Tumbuhan Asing di Indonesia. Kementrian Lingkungan Hidup Republik Indonesia Bekerjasama dengan SEAMEO BIOTROP. The Southeast Asian Regional Centre for Tropical Biology. p 169.

Anonim, 2009a. Maesopsis eminii. http://www.hear.org/pier/ species/maesopsis_eminii.htm

Anonim, 2009b. Maesopsis eminii. http://www.tropical-biology. org/research/dip/species/Maesopsis\%20eminii.htm.

Cutler, D.F. 1978. Applied Plant Anatomy. Longman. London and New York.

Esau, K. 1977. Anatomy of Seed Plants. $2^{\text {nd }}$ edition. John Wiley \& Sons. New York, Chichester, Brisbane, Toronto, Singapore.
Ginoga, K., Wulan, Y.C., and Djaenudin, D. 2004. Potential of Indonesian Smallholder Agroforestry in CDM: A Case Sudy in the Upper Citanduy Watershed Area. Working Paper CC 12, 2004. ACIAR Project ASEM 2002/066, http://www. unc.edu.au/febl/Economics/carbon/

Metcalfe, C.R., and Chalk, L. 1950. Anatomy of Dicotyledons. Vol.I. Oxford at The Clarendon Press. 405-406 pp.

McDougall, W.B. 1927. Plant Ecology. Henry Kimpton 263 High Holborn, W.C. London.

Orwa, C., Mutua, A., Kindt, R., Jamnadass, R., and Simons, A. 2009. Agroforestree Database: a tree reference and selection guide version 4.0 (http:www.worldagroforestry. org/af/treedb/)

Sass, J.E. 1951. Botanical Microtechnique. $2^{\text {nd }}$ edition. The Iowa State College Press. Iowa. USA.

Sunaryo, dan Tihurua, E.F. 2010. Catatan Jenis-jenis Tumbuhan Asing dan Invasif di Taman Nasional Gunung Gede Pangrango, Jawa Barat. Berita Biologi 10 (2): 267-269.

Uji T, Sunaryo, Rachman, E., dan Tihurua, E.F. 2010. Jenis Flora Asing di Taman Nasional Gunung Gede Pangrango, Jawa Barat. Biota 15(2): 167-173. 